\title{
Influência do trincamento da casca do ovo sobre sua qualidade comercial
}

\section{Eggshell cracking influence on its commercial quality}

\author{
Rami Fanticelli Baptista, ${ }^{*}$ Kate Porciúncula Koech, ${ }^{* *}$ Roberta de Oliveira Resende Ribeiro, ${ }^{* *}$ \\ Eliane Teixeira Mársico, ${ }^{* *}$ Sergio Borges Mano***
}

\begin{abstract}
Resumo
Com o objetivo de verificar a influência do trincamento da casca do ovo sobre sua qualidade comercial, foi realizado um experimento com 340 ovos tipo extra, íntegros, divididos em dois grupos de 170, sendo que os ovos de um dos grupos tiveram suas cascas trincadas artificialmente. Todos os ovos foram acondicionados em temperatura ambiente. Consecutivamente nos 10 primeiros dias e, depois, periodicamente, 20 ovos, 10 trincados e 10 íntegros, foram analisados, num total de 17 dias de análises, onde foram avaliados: peso do ovo inteiro; tamanho da câmara de ar; índice da gema; volume drenado da espuma da clara; $\mathrm{pH}$ da clara e da gema; e unidade Haugh. Os resultados obtidos demonstraram que o trincamento da casca do ovo influenciou negativamente em sua qualidade comercial, visto que os ovos trincados demonstraram maiores quedas nos fatores de qualidade que os ovos íntegros. Isto foi melhor verificado no decréscimo de peso, no aumento da câmara de ar, e, no volume drenado da clara, mais intensos nos ovos trincados. Sendo assim, foi possível concluir que o trincamento da casca do ovo tem influência direta na sua qualidade comercial, evidenciando, portanto, a importância da adoção de cuidados durante sua manipulação e transporte.
\end{abstract}

Palavras-chave: ovo, valor nutritivo, qualidade do ovo, trincamento.

\begin{abstract}
With the objective of verifying the influence of the cracking of the eggshell on its commercial quality, an experiment was accomplished with 360 eggs type extra, intact, divided in two groups of 180. In one of the groups, the eggs were submitted to an artificial cracking on the eggshells. Later, all the eggs were conditioned in room temperature. Consecutively in the first 10 days and, then, periodically, 20 eggs, 10 cracked and 10 intact, were used in interior and exterior quality analyses until the $27^{\circ}$ day, in a total of 17 days of analyses. The following factors were analyzed: weight of the whole egg, depth of air cell, yolk index, drained volume of albumen, $\mathrm{pH}$ of yolk and albumen, and Haugh unit. The results indicated that the cracking of the eggshell influenced negatively in its commercial quality, because the decreasing of the cracked eggs quality factors was higher than the intact eggs. This was specially observed in relation to the weight of the egg, that decreased strongly along the days; to the depth of the air cell, that had its size increased substantially; and to the drained volume of albumen, that became more intense. On the basis of this work it could be concluded that eggshell cracking has a direct influence on its commercial quality and it is important to be sure about its careful manipulation ant transport.
\end{abstract}

Keywords: egg, nutritional value, egg quality, egg cracking.

\section{Introdução}

A criação de aves de postura teve sua origem na antiguidade, pela domesticação da espécie Gallus gallus por colonizadores indianos e chineses. Posteriormente, acompanhando as tribos nômades, estas aves cruzaram a Mesopotâmia até chegarem à Grécia e se propagarem por toda a Europa. Importantes mudanças no sistema produtivo foram observadas desde então. No início da década de 1960, o avanço da tecnologia, da genética e do manejo modificaram o cenário avícola. E, nas últimas décadas, este avanço surtiu consideráveis efeitos no setor de produção de ovos, onde se destacaram criações com mais de 100 mil aves, sendo que, em alguns países, há produções com capacidade de alojamento para mais de um milhão (ANAPO, 2006).

Sobre o aspecto econômico, a China está situada como a maior produtora mundial de ovos, com uma participação de

\footnotetext{
* Escola de Medicina Veterinária, Universidade do Grande Rio - UNIGRANRIO. Rua Professor José de Sousa Herdy, 1160, Bairro 25 de Agosto, Duque de Caxias, RJ. CEP: 25071-200.

** Discente Medicina Veterinária - UNIGRANRIO.

*** Departamento de Tecnologia dos Alimentos - Faculdade de Veterinária. Universidade Federal Fluminense - UFF - Rua Vital Brazil, 64, Santa Rosa, Niterói, RJ. CEP: 24320-340.

Autor para correspondência. Rami Fanticelli Baptista. E-mail: ramifanticelli@yahoo.com.br.
} 
42\%. O Brasil ocupa o sétimo lugar no ranking, com menos de $2,1 \%$ e cerca de um bilhão de dúzias/ano. Entretanto, esta produção foi ainda maior em 2006, quando, somente nos meses de janeiro a junho, este número chegou a 1.025.991 mil dúzias de ovos, segundo análise feita em estabelecimentos com 10 mil ou mais galinhas poedeiras (IBGE, 2006).

O ovo é considerado um dos alimentos mais completos da natureza, com importante valor nutricional, enriquecido em proteínas de alto valor biológico, vitaminas e sais minerais, sendo, inclusive, utilizado no tratamento de doenças, como a anemia ferropriva, em função da grande quantidade de ferro em sua composição. Por outro lado, é utilizado com freqüência pela população brasileira, pois além de apresentar custo relativamente baixo, sua presença é constante na dieta, por fazer parte do seu hábito alimentar (SBCTA, 2006).

Cada vez mais, estudos relacionados com a qualidade do ovo têm sido realizados, pois esta mantém estreita relação com sua comercialização. Sendo assim, analisar os fatores de qualidade do produto é de suma importância para aceitação dos consumidores (Campos, 1973). Entre seus fatores de qualidade, está a integridade da casca, cuja manutenção se faz através da adequada nutrição da ave, equilibrada em sais minerais, principalmente cálcio, seguido do fósforo e do delicado balanço de sustâncias eletrolíticas para a homeostase desses minerais. Além disso, são necessários cuidados em sua manipulação, transporte e acondicionamento (Evangelista, 1992).

Os ovos, por serem produtos alimentícios delicados e perecíveis, que sob condições adversas podem se deteriorar facilmente, necessitam de cuidados especiais. Sua casca oferece uma proteção limitada, e, por seu conteúdo ser um excelente meio de cultura para o crescimento microbiano, evidencia-se a importância e a necessidade da adoção de meios e métodos relacionados com a higiene e a sanidade, para a obtenção de um produto final de boa qualidade (Katayama, 1994).

Desta forma, o objetivo do presente trabalho foi verificar se o trincamento da casca do ovo tem influência sobre sua qualidade comercial, no referente aos fatores de qualidade externa e interna, através das verificações de peso do ovo inteiro, tamanho da câmara de ar, índice da gema, pH da clara e da gema, unidade Haugh e volume drenado da espuma da clara, de acordo com a legislação vigente.

\section{Material e métodos}

O experimento foi realizado no Laboratório de Tecnologia de Aves e Derivados da Faculdade de Veterinária da UFF, onde foram utilizados 340 ovos tipo extra de galinhas da raça Hisex com dois anos de idade, separados em dois grupos de 170. Os ovos de um dos grupos foram submetidos a um trincamento, artificialmente, através de um pêndulo formado por $15 \mathrm{~cm}$ de barbante suportando um peso de $20 \mathrm{~g}$ e elevados a um ângulo de $90^{\circ}$ de onde foram soltos a cada lado do ovo, causando seu trincamento. Ambos os grupos foram mantidos, então, em temperatura ambiente $\left(\sim 26^{\circ} \mathrm{C}\right)$.

O experimento se procedeu pela utilização de 20 ovos por dia, 10 íntegros e 10 trincados, nos dias 0 ao 9, e depois nos dias $11,13,15,17,20,23$ e 26 , sendo estes submetidos às seguintes análises: pesagem dos ovos, com auxílio de balança analítica; tamanho da câmara de ar, através da demarcação da câmara visualizada pelo ovoscópio, com posterior sobreposição do ovo em uma escala milimétrica onde se constatou sua medida; altura da clara densa, realizada após a quebra do ovo, quando, então, foi aferida com o auxílio de um micrômetro; índice da gema, tomado através do resultado da aplicação dos valores da altura (medida por micrômetro) e largura (medida por paquímetro)

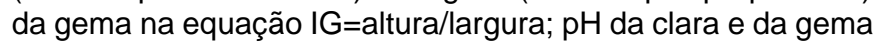
dosados por pHmetro calibrado; volume drenado da espuma da clara, verificado pelo líquido drenado, após 30 minutos, da espuma da clara feita com batedeira durante 3 minutos em velocidade máxima e colocado em funil para drenagem espontânea; e unidade Haugh, efetuada através da relação dos valores do peso do ovo e da altura da clara densa na tabela de unidade Haugh.

A análise estatística utilizada foi análise estatística de variância (ANOVA) com posterior realização do teste de média (Tukey).

\section{Resultados e discussão}

De acordo com o exposto na Figura 1, pode-se observar uma comparação entre a variação média dos pesos dos ovos trincados e íntegros durante o período de 27 dias, onde se verifica uma diminuição de seus valores explicada pela perda de água e gás carbônico, formado a partir da hidrólise alcalina do ácido carbônico (Romanoff e Yushock, 1948). Confirmando estas afirmações, o decréscimo dos pesos dos ovos trincados neste experimento foi consideravelmente mais evidenciado, quando comparado aos ovos íntegros. Perante os resultados deste experimento, verificou-se que as cascas dos ovos trincados não se encontravam impermeáveis à perda de gás carbônico, que de acordo com Romanoff e Yushock (1948), é o fator determinante na preservação da qualidade dos ovos armazenados em temperatura ambiente. A maior perda do volume dos ovos trincados quando comparado aos íntegros pode se justificar pela maior evaporação da água da clara através da rachadura na casca do ovo, fato este comprovado nas citações de Stadelman e Cotterill (1977).

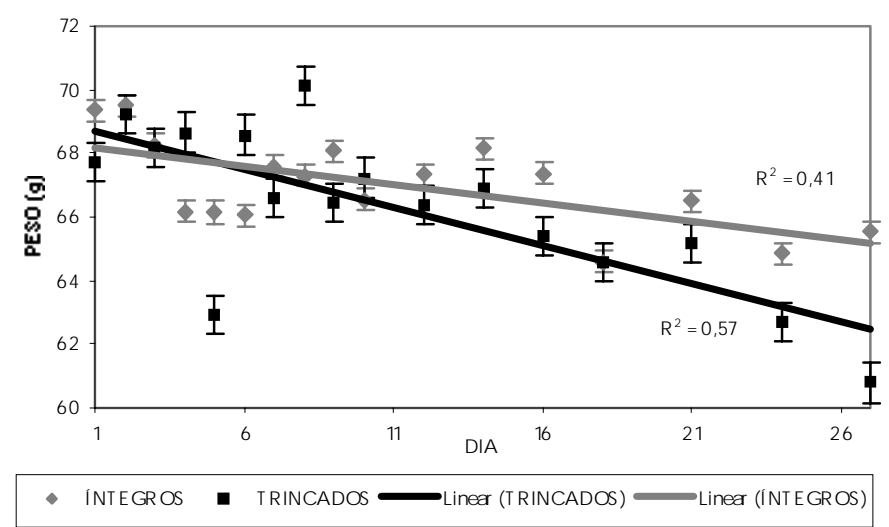

Figura 1: Comparação entre a variação média do peso dos ovos trincados e dos íntegros e suas respectivas retas de regressão e correlação

A câmara de ar dos ovos sofreu um crescimento linear ao logo do tempo do experimento, entretanto, o aumento foi mais intenso nos ovos trincados, devido à hidrólise alcalina do ácido 
carbônico, ocasionando maior evaporação da água e maior eliminação do gás carbônico, além de maior entrada de ar atmosférico devido à rachadura na casca do ovo, conforme citações de Stadelman e Cotterill (1977). Em função desta perda de substâncias em decorrência da dissociação do ácido carbônico, ocorre uma conseqüente diminuição no conteúdo do ovo, o que provoca característico crescimento da câmara de ar, o que pode ser facilitado caso haja trincamento do ovo (Alves, 1946). Observa-se, na Figura 2, que ambos os tipos de ovos trabalhados nesta pesquisa apresentaram um crescimento linear no tamanho da câmara de ar. Porém, confirmando o parecer do autor anteriormente citado, ficou evidente que os ovos trincados tenderam a apresentar esta característica de forma mais intensa.

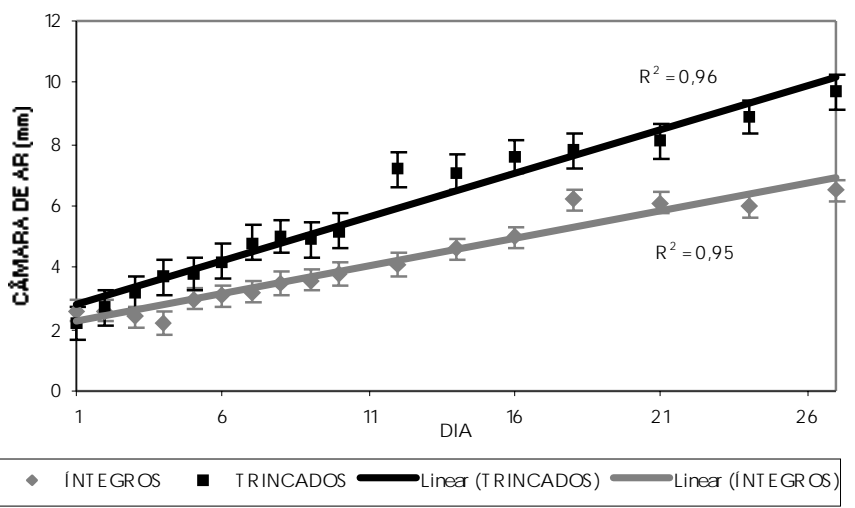

Figura 2: Comparação entre a variação média do tamanho da câmara de ar dos ovos íntegros e trincados e suas respectivas retas de regressão e correlação

Segundo Stadelman e Cotterill (1977), o índice da gema correlaciona a altura da gema com sua largura, e quanto mais distante de 1 for esta correlação, mais velho é o ovo, o que pôde ser observado nos resultados do presente experimento. Com redução média da altura da gema de $40 \%$ para os ovos íntegros e trincados, sem diferença considerável entre eles, e aumento médio de sua largura de $21 \%$, também para os ovos íntegros e trincados, o valor de índice da gema, conseqüentemente, sofreu uma constante queda para ambos os grupos de ovos. Entretanto, na Figura 3, observa-se que não existe diferença entre as taxas de decréscimo desta medida tanto para os ovos íntegros, quanto para os trincados.

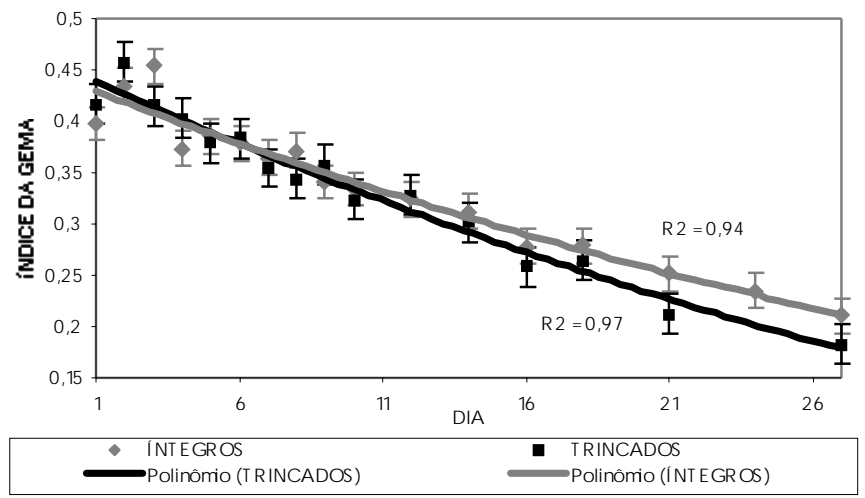

Figura 3: Comparação entre os índices da gema médio dos ovos trincados e dos íntegros e suas respectivas retas de regressão e correlação
Com o tempo de estocagem e a contínua dissociação do ácido carbônico, há conseqüente aumento do $\mathrm{pH}$ do albúmen (Stadelman e Cotterril, 1994). No presente experimento, uma comparação entre a evolução do pH médio do albúmen dos ovos trincados e dos íntegros demonstrou que o valor do $\mathrm{pH}$ sofreu um crescimento acelerado no início do período de estocagem, desacelerando a partir do 16으 dia. Este comportamento foi apresentado em ambos os grupos de ovos estudados (Figura 4).

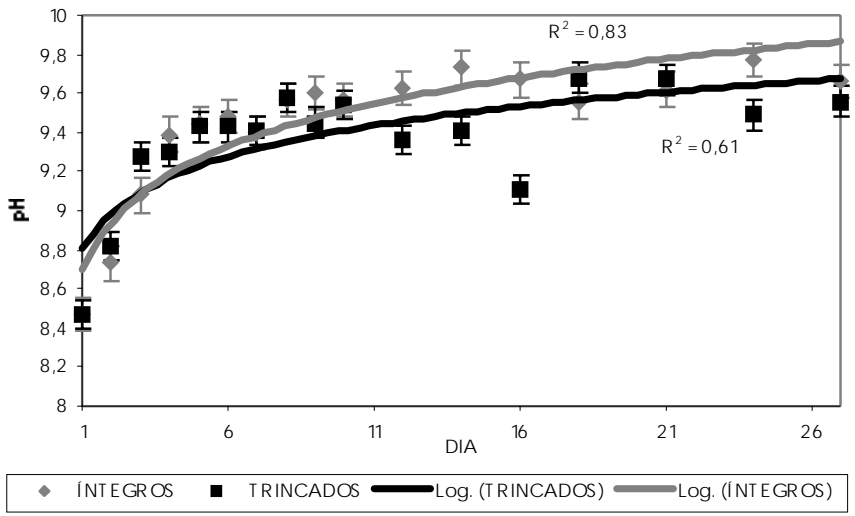

Figura 4: Comparação entre as medidas do $\mathrm{pH}$ médio do albúmen dos ovos trincados e dos íntegros e suas respectivas retas de regressão e correlação

$\mathrm{O} \mathrm{pH}$ da gema em ovos recém-postos é, geralmente, em torno de 6,0, mas durante a estocagem, o pH gradualmente aumenta para valores entre 6,4 e 6,9 (Sharp e Powell, 1931, Brooks e Hale, 1955; "American Egg Board", 1998). Na Figura 5 , pode-se verificar a comparação entre a evolução do $\mathrm{pH}$ médio da gema dos ovos trincados e dos íntegros, onde, de modo geral, notou-se um pequeno aumento do $\mathrm{pH}$ da gema tanto nos ovos íntegros, quanto nos trincados, não havendo diferença notória entre eles.

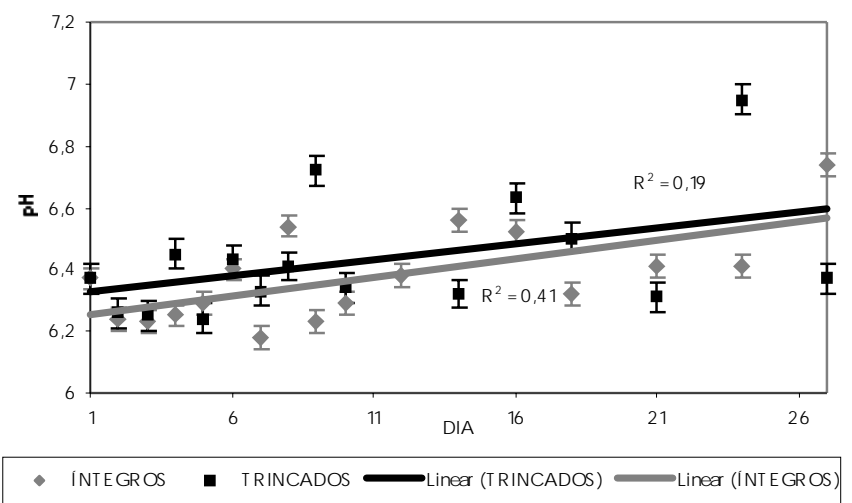

Figura 5: Comparação entre as medidas do pH médio da gema dos ovos trincados e dos íntegros e suas respectivas retas de regressão e correlação

Também em função das transformações provocadas pela hidrólise alcalina do ácido carbônico, ocorreu progressiva fluidificação da clara densa, com conseqüente perda de sua altura, mais acentuada nos ovos trincados. E, esta perda, junto à diminuição do peso do ovo, leva a uma interferência negativa sobre o valor da unidade Haugh, que relaciona estes 
dois fatores (Stadelman e Cotterril, 1994). O resultado do experimento em relação ao albúmen vai de acordo com a citação de Stadelman e Cotterill (1997), que relatam a diminuição de sua altura devido à hidrólise do ácido carbônico, que, com o passar do tempo, se torna fluido (Figura 6), embora os valores da unidade Haugh tenham sofrido queda expressiva para os dois grupos de ovos (cerca de $80 \%$ ), comparando as duas linhas de tendência, o ovo trincado apresentou uma queda ligeiramente maior que os ovos íntegros.

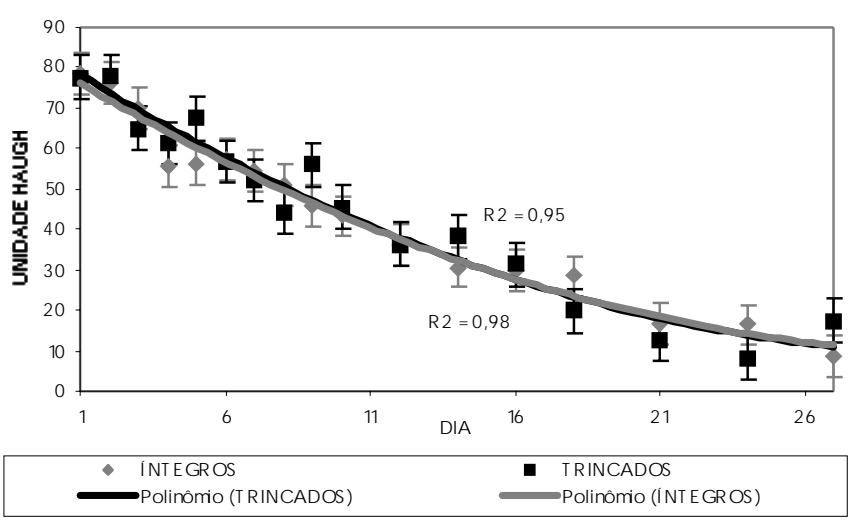

Figura 6: Comparação entre a Unidade Haugh média dos ovos trincados e dos íntegros e suas respectivas retas de regressão e correlação

Nos ovos trincados, ocorre uma maior facilidade de decomposição de substâncias como a ovomucina, que é a proteína responsável pela estabilidade da espuma. Conseqüentemente, a espuma, formada pela bateção do albúmen, até o "ponto de neve", se torna mais fluida e, com isto, há interferência sobre seu volume drenado (Campos, 1973). Esta observação pode ser confirmada neste trabalho, através dos resultados obtidos pela análise do volume drenado da espuma da clara dos ovos trincados, após 30 minutos de repouso (Figura 7), cuja representação demonstra que houve considerável aumento no volume drenado para

\section{Referências}

ALVES, N. G. O Ovo de Mercado. Ministério da Agricultura, n. 305, p. 63-78, Rio de Janeiro, 1946.

AMERICA EGG BOARD. Egg Composition Parts Basic Egg Facts, 1998. Disponível em: <http://www.aeb.org/facts/index.html>. Acesso em: 23 out 2006.

ANAPO. Associação nacional dos produtores de ovos / Portugal. 2006. Disponível em: <http://www.anapo.pt/_pages/_anapo/notID02.asp>. Acesso em: 19/12/2006.

BROOKS, J.; HALE, H. P. Strength of the shell of hen's egg. Nature, 1955.

CAMPOS, J. E. Arquivos da Escola de Medicina Veterinária, v. 25, n. 3. Órgão de Publicação Oficial do Centro de Pesquisas Veterinárias UFMG. Belo Horizonte. p. 212-215, 1973.

EVANGELISTA, J. Tecnologia de Alimentos. 2. ed. São Paulo: Atheneu, 1992. $657 p$. estes ovos. Por outro lado, os ovos íntegros não demonstraram uma tendência de alteração deste volume.

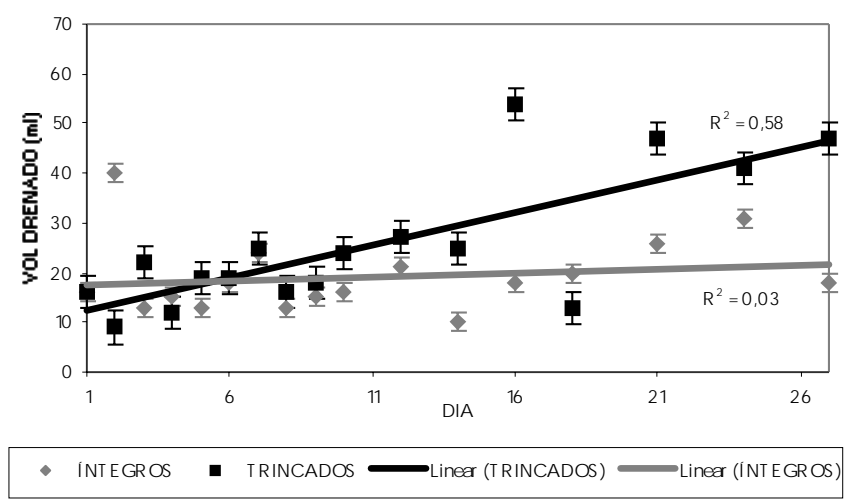

Figura 7: Comparação entre as medidas do volume drenado após 30min de repouso da clara batida dos ovos trincados e dos íntegros e suas respectivas retas de regressão e correlação

\section{Conclusão}

Com base nos resultados encontrados no presente estudo, concluiu-se que: a perda de peso, bem como o aumento da câmara de ar, dos ovos trincados são bem mais intensas do que dos ovos íntegros; não há diferença, tanto entre as taxas de decréscimo para ambos os grupos de ovos, no que se refere ao índice da gema, quanto entre as pequenas taxas de aumento de $\mathrm{pH}$ da clara e da gema; a diminuição da unidade Haugh apresenta uma queda ligeiramente maior nos ovos trincados e, também nestes, ocorre considerável aumento no volume drenado de espuma da clara, o que não ocorre com os ovos íntegros. Ou seja: a perda de qualidade é bem mais intensa nos ovos trincados do que nos íntegros. Sugere-se, portanto, que sejam aplicadas medidas de controle para que os ovos cheguem aos consumidores o mais rápido possível, devidamente inspecionados, e transportados e manipulados cuidadosamente, evitando-se o trincamento de sua casca e conseqüente perda de qualidade.

IBGE. Instituto Brasileiro de Geografia e Estatística. 2006. Disponível em: <http://www.ibge.gov.br/home/estatistica/indicadores/agropecuaria/ producaoagropecuaria/default.shtm>. Acesso em:27/12/2006.

KATAYAMA, M. C. IV Simpósio Técnico de Produção de Ovos. p. 123125. Ed. Anais, 1994.

ROMANOFF, A. L.; YUSHOCK, W. D. Preservation of Intact Eggs by Sealig with Chemical Agents. Virginia State University. 1948. p. 331333.

SBCTA. Sociedade Brasileira de Ciência e Tecnologia de Alimentos. 2006. Disponível em: <http://www.sbcta.org.br/index.php?pag=300 \&id=20060920+1 1:48:10.560019\&mes=9>. Acesso em:27/12/2006.

SHARP, P.F.; POWELL, C. K. Increase the $p R$ of the white and yolk of hen's eggs. Industry of Engineering Chemistry. v. 26, p. 196-199. 1931. STADELMAN, J. W.; COTTERILL, J. O. Egg Science and Technology. The Avi Publ, 4. ed., Connecticut, 1977. p. 1-3, 54-64, 105, 136 p. 